\title{
Tamaño y difusión. Construcciones antirracistas en alta resolución para medios peruanos
}

Size and Broadcasting. Anti-racist Issues in High Definition for Peruvian Media

Profesor en la Facultad de Ciencias y Artes de la Comunicación de la Pontificia Universidad Católica del Perú (PUCP) y profesor coordinador de los cursos de guion en la carrera de Comunicación Audiovisual de la Universidad Peruana de Ciencias Aplicadas (UPC). Es magíster en Ciencia Política con mención en Relaciones Internaciones (PUCP) y tiene un diploma y certificado profesional en Business Coaching (CENTRUM y EADA). Se interesa por investigar temas relacionados con estudios sistémicos en educación y sociedad, nuevos medios digitales, estética política, psicología política, estudios del humor y escritura audiovisual. Coleccionista de memes. 



\title{
Tamaño y difusión. Construcciones antirracistas en alta resolución para medios peruanos \\ Size and Broadcasting. Anti-racist Issues in High Definition for Peruvian Media
}

\author{
Augusto Pavel Solís López \\ Pontificia Universidad Católica del Perú \\ pavel.solis@pucp.edu.pe (https://orcid.org/oooo-0oo2-6318-9803) \\ Recibido: 02-03-2021 / Aceptado: 07-06-21 \\ https://doi.org/10.1880o/conexion.202101.004
}

\section{PALABRAS CLAVE / KEYWORDS}

Antirracismo, ignorancias audiovisuales, racismo simbólico, alta resolución, experiencias de marca / anti-racism, audiovisual ignorances, symbolic racism, high-definition, brand experiences

\section{RESUMEN}

Este ensayo reflexiona sobre cómo la alta definición digital de nuestras pantallas es un fenómeno que conjuga con la noción de racismo simbólico a través de la construcción de experiencias placenteras de marcas audiovisuales. Ello sucede porque el HD va sujeto a estructuras neoliberales digitales que llevan a obtener ingresos y fidelidad, pero que construyen paradojas de autorregulación y estructuras racistas inmutables. La interacción de los medios, los productores y las audiencias se ampara en lo que se ha nombrado ignorancias audiovisuales, creencias falsas o ausencia de creencias reales que se condicen con prácticas antirracistas cuestionables que sitúan el problema racista en lo circunstancial, sin llegar a reconfiguraciones críticas ni estructurales.

\section{ABSTRACT}

This essay discuss on how the digital high-definition of our screens is a phenomenon that combines with the notion of symbolic racism, through the building of pleasurable experiences of audiovisual brands. This happens because the HD is bound to digital neoliberal structures that lead to income and fidelity, but build paradoxes of self-regulation and immutable racist structures. Such interaction of media, producers and audiences are supported by what has been called audiovisual ignorances. These are false beliefs or absence of real beliefs which are consistent with questionable anti-racist practices that place the racist problem in the circumstantial, without reaching critical or structural reconfigurations. 


\section{Tamaño y difusión. Construcciones antirracistas en alta resolución para medios peruanos}

La resolución de la televisión peruana en la televisión digital terrestre (TDT) durante febrero de 2021 tiene las siguientes dimensiones en su alto por ancho: 1920 $\mathrm{x} 1080$ (full HD). Esto da un resultado que redondea los dos megapíxeles. Y es posible que los programas televisivos se graben en cámaras broadcast con resoluciones superiores, que luego reciben una degradación al full HD en el masterizado. También hay que considerar que, a la fecha, es sencillo encontrar, en cadenas electrónicas nacionales, televisores inteligentes que cuadriplican el full HD, comercialmente hablando, con el $4 \mathrm{~K}$. Conjuntamente, para completar la experiencia HD se requiere equipamiento en reproductores Blu-ray, sonido envolvente y soportes digitales que procesen alta resolución. Ello crea una experiencia de valor positivo en el audiovisual. Se ve bien, se escucha bien, se siente bien.

Sirve esta información de marco tecnológico y también de escenario simbólico. Este texto tiene por fin explorar una conexión entre la elevación de calidad en imagen y los discursos transferidos desde la teoría crítica de la raza (TCR). ¿Qué conecta la raza y el audiovisual? Se propone que hay poblaciones desfavorecidas por el capital y prácticas raciales, que son representadas en los sistemas de una cuando la noción de raza por tipo o linajes se amplía a una visión estructural sobre la raza como constructo social y estatus. La emisión en alta definición como sistema implica participar en órdenes en las que el racismo también es construido por algoritmos y estrategias comerciales de marca. Hay jerarquías en usos, tiempos de pantalla, etiquetas raciales y contenido propalado. Estas son mediadas por la tecnología y los modos de producción audiovisual (Almeida, 2019; Beller, 2006, 2010, 2018, 2021; Crogan y Kinsley, 2012; Steyerl, 2009; Tufekci, 2013). Por tanto, las escalas superiores acceden a mejores términos de representación y usos tecnológicos, y los menos favorecidos son conducidos a un menor acceso de tecnología y ventanas de representación. En concreto, los últimos se asocian a imágenes pobres en calidad.

Se parte de lo expuesto por el psiquiatra Frantz Fanon, quien señala el comportamiento como resulta de una situación cultural en la que los medios penetran al individuo para ejercer una visión del mundo al que pertenece (1952/2008, p. 135). Aquí aparece un espacio de disociación entre ser y no ser bajo la presión del contexto colonizador donde el hombre negro habita y donde se lo analiza (1952/2008, pp. 105-106). Por ello, una teoría de la experiencia racial debe operarse con una autoconciencia del teorizador que alumbre críticas sobre su propio racismo y su ubicación en una esfera de privilegios (Rabaka, 2010, p. 53). Esto se 
enlazará con las cuestionadas prácticas antirracistas que se expondrán adelante, ya que estas eluden cambios en procesos estructurales y de contenido en las representaciones de las poblaciones negras e indígenas peruanas.

Pero también se suma lo manifestado por Silvio Almeida sobre el racismo construido en las subjetividades, comunicadas por los medios y las industrias culturales, en donde la discriminación es cognición y emocionalidad influida por procesos heredados históricamente (2019, p. 40). Esta estructura racista en el modelo neoliberal introduce al sujeto discriminado en un sistema de crisis y contradicciones, en el que la inferioridad de su condición se enuncia en su modo de ser peligroso por ser el marginal que afecta el modelo, en lugar de también entenderlo como un resultado de las prácticas del capitalismo (2019, p. 126).

En lo expresado, hay una articulación entre la tecnología, la TCR y prácticas antirracistas, como en el caso del uso de dispositivos inteligentes en alta resolución, que brindan estatus en una estructura con contradicciones del sistema capitalista y con prácticas socioculturales dominantes. Esto, en esencia, nos muestra un espejo prístino de los horizontes racistas que creamos y nos circundan en los sistemas mediáticos digitales. Por tal razón, el objetivo central de este texto es explorar la conexión entre prácticas antirracistas cuestionables y estrategias capitalistas en medios digitales peruanos.
Este texto se inscribe en estudios de raza en sociedades mediadas por lo digital (McMillan, 2020, p. 442), en las que las economías digitales presentan la raza como una interacción de constructos socializados. Para ello, la definición sobre raza que guiará el texto será un acercamiento procedimental que parte del racismo simbólico. Este racismo explora, en grupos dominantes de blancos, cuatro puntos en los que convergen actitudes y creencias prejuiciadas. Estos puntos son los siguientes: (1) el racismo es algo del pasado; (2) las fallas de los «negros» se deben a su incapacidad para trabajar duro; (3) los «negros» hacen excesivas demandas; y (4) los «negros» han recibido más de lo que merecen (Dovidio et al., 2016, p. 268). Además, las creencias se delimitan como un proceso mental en el que el sujeto, más que tener creencias, hace creencias a través de observaciones empíricas y experiencias de vida (Österholm, 2010).

Estas creencias y actitudes muestran una defensa del racismo como cognición procedimental que opera en estos puntos: se conceptualizan descalificaciones raciales para examinar empíricamente los beneficios que han sufrido otras razas, lo que lleva a una lógica histórica que embiste lo resarcido y a un revisionismo social acrítico y parcial. Todo este procedimiento yace introducido en la estructura social, donde las anclas decimonónicas del naturalismo ilustrado que estigmatizaba razas inferiores y superiores - vinculando a paletas de colores como lo blanco, lo ne- 
gro, lo amarillo, etcétera- coexistían con el darwinismo social y el positivismo de prerrogativas raciales.

Por tal forma, la inferioridad racial ahora es codificada como el resultado que proviene de los esfuerzos y acciones de grupos o individuos para cambiar su destino. ¿Es válido acusar de racismo?, parece decirse hoy. Ello porque también se cree que la apertura del mercado que trajo consigo el capitalismo neoliberal cambió el racismo al proscribirlo y dar voz a otras poblaciones en las sociedades digitales. Empero, se amontonan categorías sociales y mediáticas en que las aspiraciones de los blancos son dominantes y las de otras poblaciones se expresan como falta de méritos, victimización o incapacidades para crearse un mejor futuro. Esto sotierra la desigualdad de oportunidades que enmascara la preservación de privilegios sociales y económicos. En síntesis, lo económico, político y social del fenómeno racismo, hoy, se cataloga bajo un procedimiento en el que creencias y actitudes en apariencia justas construyen nuevos discursos de discriminación y descalificación racial. Esto será denominado, en adelante, racismo.

Es importante aclarar que, en el contexto peruano, «negro», «trigueño», «cholo», «serrano», «charapa», «blanco», etcétera, son categorías de amplio espectro conceptual, de indefinición como fenotipos de racialización y de disputas histó- permiten delimitarlas tan palmariamente como en otros contextos sociales (Rochabrún et al., 2014; Zavala y Vich, 2017). Pero, a pesar de esto, tales nociones sí pueden ser reconocidas por las audiencias de forma práctica en los contenidos difundidos por los medios (Martínez, 2010; RT en Español, 2014; Universidad del Pacífico, 2019). Es claro el problema de agrupar esas categorías en una teoría foránea, pero aquí no se busca reducir la cuestión; más bien, se espera impulsar otros debates. En este sentido, entrecruzar lo tecnológico con la noción propuesta de racismo abre reflexiones sobre un fenómeno multifacético. Estas facetas se relacionan con experiencias comerciales en prácticas antirraciales (Beller, 2006), con la reconstrucción dialéctica de la negritud y la blanquitud (Fanon, 1952/2008), con la colonización de modos de ser por el capital (Steyerl, 2009) y con las relaciones de fuerza gramscianas entre contradicciones orgánicas y coyunturales (Gramsci, 1971).

\section{La resolución intensificada}

Hace una docena de años, la artista visual Hito Steyerl, en su famoso ensayo En defensa de la imagen pobre, señaló que la resolución era un fetiche conectado al neoliberalismo, a las culturas nacionales dominantes, a los sistemas de producción capitalista y a la adoración al genio masculino (2009, párr. 7). Como primer reconocimiento de esta afirmación, en las industrias audiovisuales el perfil promedio del productor o director reconocido es 
que sea un hombre, blanco y de mediana edad (Digital Spy, 2018). Por otro lado, la globalización ha reconfigurado la propiedad del mercado audiovisual internacional y la ha puesto en manos de unos pocos conglomerados mediáticos que tienen prácticas de dominio mercantilista (Baerga, 2015; Mancinas-Chávez et al., 2019), que difunden ideas conservadoras en ámbitos estratégicos (Barber y Pope, 2019; Santos Rutschman, 2021) y que favorecen el libre mercado (Baerga, 2015).

Bajo la forma de una crítica usando la materialidad histórica, Steyerl expone en los linderos de la media digital las concesiones a las que se someten creadores audiovisuales que necesitan producir y difundir. En territorios manejados por corporaciones y transnacionales que dominan discursos, culturas y tecnologías (Baerga, 2015), como una indagación no exhaustiva pero ejemplificadora, ¿se podría difundir una serie televisiva sobre las esterilizaciones forzadas a mujeres pobres, indígenas y de procedencia rural entre 1996-200o? Ello considerando que el broadcaster promedio peruano reduce esta violación de los derechos reproductivos a solo una noticia judicial de menos de un minuto (ATV Noticias, 2021; Ballón, 2013). Se trata de una cuestión hipotética, pero que no es antojadiza, porque este caso será usado de ejemplo en las prácticas antirracistas cuestionables. Como nota final, el broadcaster peruano también es un hombre blanco de mediana edad.
Siguiendo con la línea anterior, hay concordancia con la tesis de Steyerl (2009), que ya advertía algo similar a una jerarquía de clases entre las calidades de resolución. Esto queda manifiesto en prototipos como el 16K (15360x 8640, 133 megapíxeles), el Wide Hexadecatuple Ultra Extended Graphics Array (WHUXGA) o el ya establecido comercialmente $4 \mathrm{~K}$ de los televisores inteligentes, laptops gamers y celulares de alta gama. Contrastan con la opaca y pobre resolución Quarter-Quarter Video Graphic Array (QQVGA) de 160 x 120 píxeles de celulares o webcams de tecnología en obsolescencia. Entonces, la posesión de una imagen nítida por su resolución sobresaliente se acopla a símbolos de estatus y riqueza. Además, el celular o el televisor, además de marcas, también ostentan experiencias placenteras que prometerían la ilusión de ser ilimitadas. Un televisor es tan grande como un cine, un cine es tan ensalzado como un espectáculo en vivo, un celular es tan portátil como el cuerpo. Todos aglutinan un intercambio entre el poder de las imágenes y la reputación de poseer lo mejor que el dinero compra.

Lo que también yace anclado tras la materialidad del audiovisual en cuanto a calidad de imagen es que la técnica para estas resoluciones estará en las manos de quienes encuentren cómo costear el andamiaje audiovisual que mantenga esta infraestructura (Beller, 2021, p. 224). En palabras sencillas, como es caro grabar y difundir en $4 \mathrm{~K}$ o $16 \mathrm{~K}$, menos sujetos uti- 
lizarán esa calidad. Pero esto supera al capitalismo industrial. Cuando la producción digital audiovisual se opera como un concepto neoliberal de estructura mediática, los productores, primero, querrán obtener rentabilidad inmediata de imágenes costosas y, segundo, ostentarán discursos acordes con sus creencias. Entonces, un productor hombre blanco y de mediana edad puede difundir discursos en los que el racismo no existe o está en otros. Ello impulsa a preguntarse por una dimensión ética en la vinculación de hacer creencias en pantallas audiovisuales y las responsabilidades inseparables de los productores al hacer una comunicación que disemina racismo.

Para ejemplificar: hoy en internet se hallan contenidos audiovisuales que propalan videos con discriminación étnica-racial, los cuales representan a mujeres de la selva con cortas prendas sugestivas y textos en doble sentido. Esto genera muchos me gusta y cuantiosas reproducciones. Además, tal representación incluye una intensa reificación cuando se deduce el estereotipo de la mujer de la selva peruana. Se la presenta poseedora de una hipersexualidad muy extendida, heredada desde la visión masculina colonialista que empareja la tierra amazónica como lugar de exuberancia (Motta, 2011). Por tanto, al disfrutar y usar lo avanzado de la tecnología audiovisual, también se filtran mensajes que manifiestan racismo, sexismo y clasismo. Estos discursos tácitos y dominantes se denomina-

\section{Ignorancia audiovisual con marcas}

El filósofo Charles Mills señaló que el racismo está interseccionado con otros sistemas de dominación. En su brillante definición de la epistemología de la ignorancia, enuncia la ignorancia como el poco autoconocimiento para explorar lo que creemos de nosotros mismos o sobre los demás. Esto implica que cualquiera puede cometer ignorancia epistemológica, por ejemplo, si, cuando hace crítica racial, no contempla la internalización de sesgos cognitivos del grupo al que pertenece. Esto, en términos de raza, lleva a que un teorizador blanco y occidental, al estar inscrito en una estructura dominante y no evidenciar su ignorancia, no abroga totalmente el racismo, porque tiene privilegios raciales (Mills, 2007). Esto ya fue señalado por Fanon, quien criticó a teorizadores que no cuestionaban sus distorsiones en la psicología cuando proponían complejos como el Edipo en población negra (1952/2008). Queda manifiesto con Mills que enunciar la ignorancia es comprender que existen interacciones entre creencias y agentes que dan forma a la adquisición de conocimiento. La ignorancia, en este sentido, es definida como aquellas creencias falsas y también la ausencia de creencias reales que parten de un proceso mental que hace basado en experiencias subjetivas y observaciones empíricas (Mills, 1991, 2007; Österholm, 2010).

Se propone que las ignorancias en las interacciones del entorno mediático ali- 
mentan los discursos raciales con conformismo. Porque se puede conocer que algo está mal, pero, si ha funcionado por un tiempo, es recomendable que continúe, ya que no se sabe hacer algo distinto en los contenidos mediáticos. Ello es palpable, por ejemplo, en las decisiones de quienes manejan la televisión peruana: broadcasters hombres y blancos. De tal forma, en la crítica racial, la ignorancia audiovisual es una operación que se amplifica por las diferencias sociales y que se enmascara con la evolución de tecnologías audiovisuales. Se anota, por último, que podría construirse un proceso de transformación si se discuten las responsabilidades sobre la ignorancia y se asumen compromisos para la crítica estructural.

En la última década, hubo un rebrote de la comunicación de noticias falsas y teorías conspiranoicas. Esto apunta a que un grupo de productores audiovisuales tiene el poder de crear en brillante calidad ignorancias que deliberan en temas como la raza, la salud pública, la igualdad de género, entre otros, pero sin responsabilidad o compromisos éticos. Todo para consentir, muchas veces, que no haya cambios estructurales o que haya debates en ignorancia sobre la raza, la equidad, el clasismo, el sexismo, el capitalismo, etcétera. Con ese hilvanado de contenidos, se generan más recursos, más inversiones y más capital.

La operación que le permite al capital, circulando en el aumento de resolución, que origine ignorancias audiovisuales con reconfiguraciones sociales, culturales e históricas tiene que ver con la economía de la atención y las audiencias (Beller, 2006; Franck, 2019; Goldhaber, 2006). De acuerdo con esto, en redes sociales, en televisión, en el cine, en videojuegos, la audiencia obtiene un placer de enganche al ver discursos o ideas en consonancia con sus necesidades. Los algoritmos, las mediciones de rating de televisión abierta, el tiempo de conexión al streaming, las suscripciones y los boletos de taquilla, todos compiten por conquistar la atención, que será intercambiada en el mercado digital neoliberal por ingresos monetarios.

Entonces, si hay competencia continua entre las plataformas, la solución para monetizar es crear un atributo intangible que origine fidelidad a través de construcciones mentales, donde la suma de lo negativo y lo positivo dé una percepción de identidad y grupos sociales. En pocas palabras, se trata de una aproximación a la definición de branding (Heindrichs, 2019; Hoyos, 2016; McMillan, 2020). Esta es la regulación para modelar en la estructura mediática neoliberal: gran resolución de imagen, experiencias de marca, puntos de contacto y viajes de consumidor. Una operación que transforma la marca en experiencia placentera. Las marcas son YouTube, Facebook, TikTok, Disney, Netflix, Amazon Prime, HBO Max, Nintendo, Rockstar Games, Latina, América TV, etcétera. 
$\mathrm{Y}$, en el terreno de competición, la materia del branding indica que hay que potenciar las experiencias positivas que asocien posibilidades de enganche, y erradicar las experiencias negativas que desconecten de la marca (Khajeheian y Ebrahimi, 2020; McMillan, 2020). Exponer en imágenes HD injusticia racial, prácticas racistas, corrupción, etcétera, ¿puede generar tracción positiva? Depende. Y, si se da esto, ¿cómo lo genera? El conocimiento en marketing responde: la atención es la satisfacción de necesidades que crea ventajas competitivas, exteriorizando una experiencia inmersiva, personalizada y con calidad (Heindrichs, 2019). Dicho de otra forma, existe el espacio para debatir en los contenidos audiovisuales. Empero, por la competencia y los costos de la calidad audiovisual, en el terreno se prefiere mostrar contenidos que enuncian falsas creencias o ausencia de creencias reales, basadas en lo empírico y lo subjetivo.

Cuando aparecen imágenes usando las ignorancias audiovisuales en las audiencias, el espacio para la crítica auténtica es difícil. Porque no son sencillas, son contradictorias, no hay tiempo de pantalla y no da placer hablar de estas. Esto, trasladado al racismo, empuja a lo que se denominará como prácticas antirracistas cuestionables, prácticas que se estructuran en acciones mediáticas que aparentan crítica al racismo, pero que no se sostienen porque son, en rigor, ignorancias, ya que evaden la autoconciencia de participar en la estructuración dominante racista y no tienen un compromiso ético para transformar la estructura.

\section{Experiencias placenteras y racismo}

Hay una línea clara. El valor de una marca decrece si las campañas salen mal o si hay polémica en los contenidos de un canal de televisión o si un anunciante se liga con insatisfacción de necesidades. Este es un punto crucial. El racismo, como lo señaló Mills (2007), jamás podrá ser personal. Es estructural, porque está conectado a prácticas, reconocimientos y experiencias sociales e institucionales que debemos concientizar y evidenciar. Por tanto, ¿cómo se hablará del racismo en tanto fenómeno estructural que atañe a la comunidad si lo vigente en el mercado audiovisual es el discurso placentero y subjetivo?

Primero, hay que ver el manejo de riesgos como un mecanismo de decisión para entender los discursos audiovisuales, ya que señala los tránsitos de lo difundido y lo descartado. Lo que aparece en pantallas son elecciones editoriales y cimentación o explotación de coyunturas sociales (Baerga, 2015; Beller, 2018). Por ello, hay un amplio espacio para conjurar una mala representación de nociones raciales, perspectivas teóricas erróneas, una simplificación de injusticias, la autonegación de estereotipos raciales, las falsedades, las medias verdades y lo que sea susceptible de distorsionarse; si la marca lo necesita. 
Para ejemplificar esta condición en el mercado peruano, ¿por qué se siguen utilizando modelos europeizados en las piezas publicitarias de tiendas por departamento? O la propensión de los informativos a buscar infractores de la cuarentena por la COVID-19 en distritos periféricos de Lima, o vendedores informales buscando el sustento diario a pesar del peligro y las restricciones. En estos últimos dos ejemplos, revela mucho que sea preponderante el origen étnico afrodescendiente o indígena de los entrevistados peruanos.

Es claro que los estados de excepción en Latinoamérica acrecentaron la situación de desigualdad y pobreza de la población vulnerable (Estupiñan Achury, 2020). Vulnerable justamente por estar fuera de la estructura neoliberal imperante y bajo marginalización racial. No es propósito de este texto, pero cabría indagar en los mecanismos surgidos para combatir el desamparo de grupos raciales por la pandemia. Por mencionar un par, están el lanzamiento de la Escuela Virtual de Jóvenes Líderes Afroperuanos por la Asociación Negra de Defensa y Promoción de los Derechos Humanos (ASONEDH) y Ashanti Perú, y el programa Jueves Afroperuanos por el Facebook Live de Ashanti Perú. Son iniciativas loables, construidas alternamente a los medios dominantes mediante streaming y con poca difusión.

Lo segundo recae en que la economía de atención plasmada en pantallas de gran nitidez necesita de la participación acti- va de las audiencias pidiendo contenidos digitales que generen cadenas de lealtad y disfrute (Khajeheian y Ebrahimi, 2020, pp. 259-260). Esto inquiere sobre el vínculo del tipo y calidad de imagen como analogía a la invisibilización de la población afroperuana, cuya contribución en la peruanidad se rastrea en la culinaria, el baile, la lírica, la música, la religión, entre otros (Valdivia Vargas, 2013, p. 204). Notado su aporte extenso, ¿cuáles son los caminos para que el afroperuano entre en las cadenas de lealtad y disfrute que se construyen en los contenidos mediáticos peruanos? Siquiera se ha planteado representar fielmente al pueblo afroperuano en las economías de atención. Ejemplos en publicidad, como las campañas de gaseosa Inca Kola o avícola San Fernando, proponen representaciones. Pero lo afroperuano es un segmento en piezas de 30 segundos, en las que son elementos de lo diverso sin ahondar más, lo cual muestra que la generación de contenidos de lo afroperuano cae en lo superficial y ocasional.

En esta línea, hay decisiones para competir por la atención del contenido audiovisual usando experiencias placenteras de marca. Entonces, como ya se señaló, los productores de contenido pueden acentuar lo problemático, hacer simplificaciones o negar lo que es factual, siempre que esto genere réditos (RT en Español, 2014; Sullivan, 2014; TeleSUR tv, 2014; Universidad del Pacífico, 2019). En última instancia, se amparan en costumbres lega- 
les como la autorregulación, que se nota agrietada muchas veces al intentar frenar efectivamente problemas ético-comerciales (Santos Rutschman, 2021).

\section{Participación activa en alta definición}

Las participaciones de las audiencias se materializan en acciones relacionadas, como la sintonización, la suscripción, la compra, el compartir, el comentario, por mencionar las más relevantes. Pero - que quede anotado-, dentro de los universos digitales, las acciones de los sujetos son vastas y sutiles, y se incluyen en narrativas desde lo abstracto racionalizado hasta la excitación más sensorial (Perniola, 2000/2004; Steyerl, 2009).

Aquí salta la paradoja sobre el proceso de vinculación de las poblaciones afroperuana, andina y amazónica, que, al usar dispositivos en alta definición entran en el universo digital. Y, al unísono, sus representaciones desde las estructuras mediáticas son cuestionables. Hay participación y discriminación operando como engranajes del sistema audiovisual racista, en el que se compele al sujeto como pieza de información para informes de resultados y se le pide lealtad, que será monetizada, pero se pasa de largo en presentar sin ignorancias su identidad y sus demandas.

Beller lo manifestaba al reflexionar sobre el capitalismo. En el mundo digitalizado, lo que se distribuye son estados emocio- nales en los que, al unísono de expandir configuraciones de lo sensorial, que aquí se las llama participaciones, lo que se expande también son los modos de producción capitalista (2018, pp.158-159). Como queda indicado, estos modos van conectados a distintas audiencias consumiendo y a otros grupos produciendo audiovisual. Queda vinculante el marco de experiencias placenteras para presentar discursos de ignorancias audiovisuales en los que las emociones son mercantilizadas. Y el racismo, soslayado.

Las ignorancias audiovisuales no llegan hacia las audiencias solamente; estas también las incentivan con su participación. Para el racismo, pueden proponerse conjeturas en torno a dos personajes creados por el humorista Jorge Benavides: la Paisana Jacinta y el Negro Mama. Jacinta encarna un estereotipo de mujer indígena, con maquillaje marrón y trenzas, polleras, dejo andino, español «mal dicho», bastante procaz y violenta. Mama, un estereotipo del negro peruano, de labios enormes, pelo hirsuto, ropa urbana, uso de jergas, aparenta ser tonto, pero suele timar al final. Ambos personajes existen desde la década de los noventa en la televisión peruana, y solo por mandato judicial el personaje de Jacinta dejó de emitirse en 2020. Mama continúa y, hasta el momento, aparece en las redes audiovisuales del canal Latina.

Entonces, ¿la audiencia pudo influir para que la Paisana Jacinta o el Negro Mama 
duraran tanto al aire? ¿Afectaba legítimamente a sus audiencias el rechazo de colectivos sociales e instituciones peruanas e internacionales? ¿La imagen que presentaban era entendida como estereotipos negativos por las audiencias que reían? ¿O para un grupo pudo ser, más bien, el ejemplo de la viveza del hombre negro o de la mujer andina, que dejaban en ridículo a los demás y con eso ganaban siempre? Como hay ignorancia audiovisual, si te ha hecho reír tanto tiempo, por qué cambiarlo. En suma, al ver esta interacción horizontal, se incide en una relación de participaciones colegidas entre audiencias y productores para la difusión de racismo en medios peruanos.

Se trata de una relación instalada en la sociedad, en la que la vivacidad del ${ }_{4} \mathrm{~K}$ impulsa una predilección por el contenido ultradefinido que aumenta nuestra forma de testificar lo que es o no es. En consonancia, el ver con detalle en pantallas de gran nitidez a color configurará repercusiones en los imaginarios de productores y audiencia. Cuando al hombre afroperuano se lo representa como Mama o a la mujer andina como Jacinta, estas imágenes son una evocación de las tensiones que Fanon señalaba entre la blanquitud y la negritud. Originan enajenación para mantener formas de explotación y dominación (1952/2008).

Las paradojas, usadas por medios audiovisuales para generar experiencias placenteras de marca, son un terreno de autorregulación en racismo. Estas paradojas son los derechos y privilegios asociados a fenotipos raciales, o riquezas y posesiones conectadas a etnias y accesos a la cultura dominante (Universidad del Pacífico, 2019). Pero no son enunciadas abiertamente; para enmascararlas, se utilizan ignorancias audiovisuales. Algo para vislumbrar en el racismo que se vive en nuestras sociedades latinoamericanas es que la superioridad sobre la base del poder capitalista se mezcla con clasismo, por lo que se discrimina más a gente pobre que se ve más oscura (Martínez, 2010, p. 125).

Empero, expandiendo lo reseñado por Martínez, hay más dispensas que el dinero en el racismo de las sociedades digitales. La imagen en HD da privilegios. Porque tener belleza, juventud, buen vestir, locuacidad o talento artístico enmascaran el racismo. Además, estas cualidades se registran pulcras y brillantes en las cámaras HD. Con estas experiencias de marca, las audiencias se mueven entre ciclos de apoyo o abandono. Aquí el cuestionamiento es si la tecnología de alta resolución que intensifica las experiencias también cosifica a los sujetos vistos e instala distancias entre las audiencias y sus juicios, para que el racismo se internalice, pero no se reconozca.

Posiblemente un gran porcentaje de la población peruana identificaría el racismo en un video de la surfista Vania Torres maquillada como una mujer anciana de la sierra 
peruana (24 Horas, 2020), y visionado exponencialmente en redes sociales y televisión. Torres ha oscurecido la piel de su rostro con base; la cámara HD de su teléfono registra nítido su objetivo: caracterizar a una mujer con arrugas, sequedad de piel y cabello cano, que se expresa con una voz aguda, quejosa y masticando el español. Un símil cercano a la Jacinta de Benavides.

En este discurso, la interrogante directa es, si se consigna el menoscabo de raza, género y clase, ¿cuál de estos dominó para que Torres escogiera su caracterización? ¿Y dónde fue que ella aprendió que debía ser vista y escuchada de esa manera? Si se continúa indagando sobre la manifestación racista, ¿qué ha reflejado este racismo en la audiencia? Porque es válido conjeturar que un porcentaje de esta, tras identificar el racismo, evidenciaría en otros contextos una similar mella de la identidad de las mujeres que viven en la sierra. ¿Pero sucede? Parecería, entonces, que las prácticas antirracistas que surgen con escándalos mediáticos son filtradas por ignorancias. Ello introduce la noción gramsciana de que las fuerzas en los sistemas operan con contradicciones orgánicas, las permanentes, y las contradicciones coyunturales, las accidentales (Gramsci, 1971, p. 176).

En un territorio marcado por los discursos intensificados y el capital, como lo es la producción audiovisual en cantidad y calidad HD, ¿cómo se darían estas inter- ciones de cada interlocutor? Como ya señalaron Sullivan (2014) y Mills (2007), un entrampamiento social al hablar del racismo es que no se busque erradicar las prácticas raciales en el conjunto, sino probar individualmente que se es liberal y distante del racismo. Esta es la alta resolución de algunas prácticas antirracistas cuestionables, mediadas por experiencias de marca.

\section{Los giros de las prácticas antirracistas}

Para distinguir el conjunto de acciones antirracistas cuestionables que usan las ignorancias audiovisuales, es necesario sumergirse en un entramado de funciones relacionales circunscritas en los debates de la TCR, el racismo y el antirracismo (Al Jazeera English, 2017; Beller, 2018, 2021; McMillan, 2020; Mills, 2007; Sullivan, 2014). La premisa inicial es que la autorregulación del racismo es paradójica y se enuncia con prácticas antirracistas cuestionables sostenidas por creencias falsas o ausencia de creencias reales basadas en observaciones y experiencias, es decir, por las llamadas ignorancias audiovisuales. Esto se asienta en una correlación de dos fuerzas en la estructura dominante (Gramsci, 1971) de los medios audiovisuales: (1) las fuerzas que tienen contradicciones orgánicas, presentadas en derechos, privilegios, dominación y discriminación asociados a grupos sociales jerárquicos con gran acceso tecnológico y representación, y la inferioridad, in- 
visibilización, explotación y opresión de otros grupos sociales subordinados, sin mucho acceso tecnológico ni representaciones reales; y (2) las fuerzas que tienen contradicciones coyunturales, cuando aparece el choque entre ambos grupos por escándalos mediáticos o contenidos de experiencia de marca errados.

Esta dinámica de fuerzas permite que, cuando las marcas exhiban contenido racista, reciban denuncias, ataques y una corriente que enciende las redes digitales. Con paciencia, estas marcas palían sus errores llamando a un equipo de creativos y relacionistas públicos, que reconfigurarán experiencias placenteras como un espacio para ser antirracista, pero, mientras sea posible, sin cambiar las estructuras ni criticar los poderes o privilegios que originaron el racismo.

En esta tensión de fuerzas, hay una horizontalidad, porque las experiencias buscan mensajes generalistas a través de editoriales, comunicados y disculpas. Así, permanece un discurso que retrotrae los deslices de las prácticas racistas de marcas y plataformas, y los convierte en yerros involuntarios que se corregirán. Nótese el verbo en futuro. ¿Qué sucede luego? Al parecer, lo mismo, es decir, no mucho. Se entiende que hacer el bien antirracista propuesto por las marcas audiovisuales como experiencias placenteras también tiene el efecto de practicar una inmutabilidad racista estructural. Y esto se enmarca en un audiovisual que senso- rialmente hace sentir bien. El circuito de un mundo en HD perfecto con la mínima acción permitida queda encendido permanentemente.

¿Cómo un peruano responde al racismo en HD? La respuesta tendrá mucho que ver con la interiorización de su racismo simbólico y su permeabilidad a observar las estructuras raciales paradójicas e inmutables en sus grupos sociales y la sociedad. Vale recapitular que el imaginario de la alta resolución tiene un lado visible, que es una sucesión de imágenes y programas nítidos, y un lado oculto, que son las prácticas comerciales para crear estas imágenes y los contenidos ideológicos para dar experiencias placenteras (Beller, 2018; Martinot, 2015; McMillan, 2020). Además, las respuestas de los sujetos interpelados ante el racismo son un abanico amplio de juicios sociales y conductas (Stamps, 2020, p. 125), pero este texto identifica de manera inicial cuatro procesos generales, sin ser exhaustivos.

Un primer antirracismo es el que señala la culpa en el otro que es racista. Propone dualidades, en las que hay blancos racistas o cholos resentidos, por ejemplo. Figuras como el racismo invertido o el racismo involuntario surgen de este espejismo. Esta es la presunción de que, si denuncio y condeno, soy inocente (Jensen, 2015, pp. 93-94), o de buscar la absolución más que saber: aunque el sistema racista continúa, uno ya no aparece racista (Applebaum, 2015, pp. 3-4). Se toma como caso la co- 
bertura del juicio por las esterilizaciones forzadas a mujeres durante el Gobierno de Fujimori (ATV Noticias, 2021). Los comentarios alrededor del aplazamiento mencionan injusticia por las mujeres o elogios a la figura de Fujimori. Aquí el hecho se enjuicia por culpable o inocente, por lo que la sentencia declarada basta. Pero no es necesario observar los basamentos de una política pública de esterilización dirigida a 270 ooo mujeres adultas (Ballón, 2013) que sufrieron una violación de sus derechos humanos y su fecundidad, además de ser operadas porque se las veía con muchos hijos, pobres y de razas indígena o negra. Este ver al otro racista y nada más, construido desde los medios y con la participación de la audiencia, obstaculiza eliminar las injusticias raciales en las estructuras sociales, ya que no revela los poderes detrás de estos discursos mediáticos ni tampoco se corrigen los privilegios (Zavala y Vich, 2017, pp. 20-21). Sin embargo, sí determina una experiencia positiva, que es validada en los medios y se ve muy bien, por lo agradable de no ser racistas. Pues otros lo son.

El segundo proceso de práctica antirracista está conectado con iluminar el tiempo pasado del racismo. Ante una denuncia de racismo, la respuesta será la confirmación de un pasado errado, representado en padres o abuelos. Y se refrenda que no se ha aprendido nada hasta ahora. Vuélvase sobre el caso de las esterilizaciones forzadas. Aparecen comentarios que refieren que las esterilizaciones pertenecen a un pasado de discriminación, en el que la justicia todavía no ha actuado y hay impunidad, considerando incluso que no se habla mediáticamente del tema en el Perú. Lo que conciben tales comentarios es la ligazón a justificaciones del pasado, en las que, como no hay solución, el racismo permanece. Entonces, la sociedad peruana no cambiará, porque hay un determinismo y prevalecen discursos racistas de siglos que explican que se abuse y esterilice a mujeres indígenas y negras. Esta sombra de pesimismo sepulta posibilidades de acciones en el presente, porque hay un conformismo moral. A esto se le suma una iluminación racial, porque se es consciente de esta inexorabilidad histórica. Y el peor efecto de esta reflexión, si ni el infalible tiempo ha cambiado el racismo, es que solo queda hacer nada (Jensen, 2015; Sullivan, 2014). Las disculpas para la inacción ya fueron dadas y el peso de lo histórico-social de la estructura racista es irrevocable.

Un tercer proceso de práctica antirracista se construye cuando se sentencia que las razas no existen (Dovidio et al., 2016; Mills, 2007), porque lo que hay son peruanos dominando y siendo dominados. Entonces, los estudios de raza deben corregirse para dar espacio a una crítica de los modos de producción y los cruces socioculturales-biológicos que hemos vivido (Rochabrún et al., 2014, pp. 24-25). $\mathrm{Y}$, ausentes las razas en blanco, cholo, mestizo, no se alimenta el racismo, lo cual permitiría ocuparse del punto cen- 
tral, que es la discriminación. Durante el juicio de las esterilizaciones forzadas, la estrategia de la defensa de Fujimori adujo que la falta de traductores que pudieran interpretar a las víctimas quechuahablantes podía incurrir en un vicio procesal. Y la audiencia se pospuso. Los comentarios posteriores criticaron que la falta de previsión del Ministerio Público pasaba por una discriminación institucional. El punto de debate versa en que no solo es discriminación; también existe un racismo estructural. Las mujeres esterilizadas lo fueron porque eran pobres, de razas indígena y negra, y se las operó en condiciones insalubres, lo que causó la muerte de varias de ellas. Todas son condiciones de denigración e invisibilización, vistas por Almeida (2019), al explicar el racismo estructural contra las mujeres.

Cuando se emplea este antirracismo, se enarbola un progresismo fuerte $y$, de nuevo, la iluminación racial. De modo contrario a colgarse de un pasado determinista, surge un proceso superpuesto de cambio perpetuo, y por ello se deben reevaluar conceptos antiguos o que tuvieron sentido antes, pero hoy ya no. Esta es una ilustración racial, en la que el cambio ocurre en los términos de la discusión, y se dejan en un lugar secundario las prácticas, los símbolos y las estructuras que crearon la discusión. Una vez que no se usen etiquetas raciales, por un discernimiento moderno del fenómeno de la raza, eso debe llevarnos a superar el racismo, pues otro es el problema. ¿Cuál? ¿Dominación, je- rarquización, mistificación, explotación? Con respecto al racismo, si no lo veo, no existe. Como se mencionó previamente, la resolución de las pantallas ciega lo que está fuera del encuadre.

Un cuarto proceso de práctica antirracista ocurre en sujetos conscientes de la culpa en la sociedad, y hasta la propia. Cargando con el peso de la vergüenza, ofrecen a las víctimas de racismo una reparación (Dovidio et al., 2016, p. 280). El enunciado es este: te pido perdón por lo que has vivido y simpatizo contigo. Pero este proceso es conflictivo por su condescendencia con los que sufren -y han sufrido- racismo. Al zanjar la culpa de manera inmediata, se es expedito para rotular el acto racista. Lo que detiene esta rapidez es una reflexión de las estructuras racistas, identificar a los agentes racistas y, sobre todo, una imposibilidad de escucha al otro. Como un carrusel trepidante de ideas aprendidas, el antirracista sabe, tiene la solución y es paternalista. En el caso de las esterilizaciones forzadas, el rol de los broadcasters peruanos es infame. Han ejecutado una extensiva ceguera local a este caso reconocido. Fueron mayormente los medios internacionales los que cubrieron por años el caso de las esterilizaciones forzadas, mientras que medios locales lo tocaron de soslayo. Las decisiones de estos broadcasters, hombres blancos y de mediana edad, durante décadas han dejado en claro que el sufrimiento o sanación de estas mujeres violentadas obtiene poca validez en sus discursos y poco tiempo de pantalla. 
Cuando se habla de las esterilizaciones desde medios peruanos como la televisión, aparece un monólogo para zanjar el debate, enaltecer alguna ayuda ofrecida a las víctimas o fabricar una leve sensación de justicia. Pero, en su arreglo juicioso, solo ha dejado ver el punto de vista de quien domina la estructura mediática y no ha experimentado racismo.

Esta sucinta relación de procesos antirracistas cuestionables no busca ser hallazgos taxativos, sino, más bien, puntos de partida. Esto se conecta con lo expresado por Almeida (2019), Fanon (1952/2008) y Mills (1991, 2007) al sopesar la crítica de la raza con la internalización de procesos sociales subjetivos que circundan el racismo. Siendo uno parte de esta estructura, consciente o velada, aparece un espejo de fuerzas gramscianas, conductas e influencias que desembocan en estructuraciones raciales paradójicas y que, al parecer, esperan ser inmutables por estrategias comerciales del capital. Esta estructura alcanza ribetes en lo tecnológico al entender lo que Steyerl dijo acerca de la imagen pobre como émulo de condiciones materiales subordinadas y jerarquías sociales en sociedades pluriculturales. Lo paradójico de las experiencias de marca con la nitidez de las altas resoluciones, cuando tenemos tanta diversidad, es que crean puentes entre las facetas de dominación y la explotación de nuestras creencias. Y dejan un espacio muy amplio para definirlas desde lo

\section{Reflexiones finales}

El racismo simbólico ocurre cuando los sujetos de un grupo asumen una posición individualista y conservadora, para juzgar las condiciones materiales de las víctimas del racismo, sin verse racistas. Este texto partió de enlazar tal racismo operando en la construcción de ignorancias audiovisuales, creencias falsas o ausencia de creencias reales basadas en experiencias y observaciones, con estrategias comerciales que buscaban generar experiencias placenteras de marca para ganar mercado, audiencias y, finalmente, rentabilidad. La brillante imagen en alta resolución es una característica servicial a estos fines, pues posibilita un encantamiento en lo sensorial y también una restricción útil para los pocos que poseen los modos de creación y las representaciones.

Las facetas de este fenómeno desembocan en prácticas antirracistas cuestionables, en las que los cambios reales en las representaciones de personas negras e indígenas y en los procesos estructurales del racismo en la sociedad peruana son eludidos por los agentes que manejan el capital y la creación en alta definición. Esto llevaría en sí las tensiones de la blanquitud y la negritud, los modos del ser colonizados en el capital, y una relación de fuerzas sociales orgánicas y coyunturales. Estas prácticas antirracistas apuntarían a ver en otros el racismo, o a cargarlo con un peso histórico determinista o con una 
adecuación de términos para actualizar el debate, $y$, por último, a aceptar el racismo con los filtros de una visión paternalista sin escuchar al otro.

La estructura racial es política y capitalista. Y, ante ella, las representaciones de los pueblos afroperuano o indígena, subordinados y enajenados en la sociedad peruana, devienen en el reclamo por afirmar críticamente sus identidades colectivas y políticas. Tales identidades se hallan ante la tarea de aprender el lenguaje con el que se construyen las experiencias de marca audiovisuales, y subvertir sus condicionantes ligadas únicamente a la rentabilidad del capital. Luego, deben llegar a afianzar marcas audiovisuales, entendidas como plataformas y canales. Es necesario que, en sus agendas, evidencien las ignorancias audiovisuales y las prácticas antirracistas cuestionables que aparecen como propuestas de autorregulación, pero que, en esencia, son paradojas para conseguir una inmutabilidad estructural racista. Para impulsar una responsabilidad en la transformación dentro de la estructura mediática, deben fomentar unos compromisos éticos que rehúyan varios productos actuales.

Esta aspiración de las reconfiguraciones sociales, políticas y del capital pasa por reconocer las diferencias, lo inacabado y lo imperfecto de las estructuras mediáticas peruanas, que tienen en sí mismas un racismo estructural. Luego, también debe mostrar lo heterogéneo, ruidoso y fragmentado de las representaciones afroperuanas e indígenas en los medios, apelando a colectivos e instituciones para crear imágenes no tan pulcras e inmaculadas como el idealizado HD, que las replanteen más diversas, cercanas y sin infulas, emitidas tanto en baja definición como en alta resolución. Estas acciones hoy emergen de colectivos como Ashanti Perú o ASONEDH, que operan en plataformas streaming; o mediante la realización audiovisual, en ejemplos como el del documental El quinto suyo. Afrodescendientes en el Perú, producido por la institución Cimarrones (Espinoza, 2002); o en talleres virtuales como Capacitación para Mujeres Afroperuanas sobre Plan de Desarrollo Concertado y Recordando Nuestra Historia, Fortaleciendo Nuestra Identidad, del Centro de Desarrollo de la Mujer Negra Peruana (CEDEMUNEP); o con el proyecto testimonial Vivencias de Afroperuanos de la Tercera Edad en Cañete, de la Asociación Pluriétnica Impulsora del Desarrollo Comunal y Social (APEIDO); o con el IX Seminario Internacional: República, Racismo y Pandemia; o con la revista D' Cimarrón; o mediante el proyecto de refuerzo de la identidad de la niñez afroperuana Palenque Infantil, del Centro de Desarrollo Étnico (CEDET); entre varios más. Tales iniciativas podrían, con mayor difusión y articulación en la alta definición, ayudar a instaurar creencias reales basadas en sus experiencias y observaciones sobre la situación problemática y dura del racismo en los medios y la sociedad peruana. 


\section{REFERENCIAS}

24 Horas. (2020, 15 de agosto). Medallista Vania Torres es acusada de racista [Video]. YouTube. https://www.youtube.com/watch?v=e3Qc850KLZw

Al Jazeera English. (2017, 2 de marzo). Stuart Hall - Race, gender, class in the media [Video]. YouTube. https://www. youtube.com/watch?v=FWP N FoW-I.

Almeida, S. (2019). Racismo estrutural. Sueli Carneiro; Pólen. http://blogs.uninassau.edu.br/sites/blogs.uninassau. edu.br/files/anexo/racismo estrutural feminismos - silvio luiz de almeida.pdf

Applebaum, B. (2015). Flipping the script... and still a problem: Staying in the anxiety of being a problem. En G. Yancy (Ed.), White self-criticality beyond anti-racism: How does it feel to be a white problem? (pp. 1-20). Lexington Books.

ATV Noticias. (2021, 11 de enero). Alberto Fujimori no se presentó en audiencia por el caso de las esterilizaciones forzadas [Video]. YouTube. https://www. youtube.com/watch? $\mathrm{v}=\mathrm{Gi} 3 \mathrm{HstNt} 3 \mathrm{X} 8$

Baerga, V. (2015). El rol de los conglomerados mediáticos en los procesos políticos de la región. En F. Sierra Caballero, P. Villegas, O. Rincón, Á. Badillo, F. Saintout, C. del Valle, O. León, I. Ramos, M. Cerbino, C. Mier, G. Coronel Salas y C. Maldonado (Eds.), $X$ Aniversario Telesur. Congreso internacional Comunicación e Integración Latinoamericana desde y para el SUR (pp. 21-32). CIESPAL. https://ciespal.org/wp-content/ uploads/2015/o7/ACTAS-TELESUR-FINAL-11-01-20171.pdf
Ballón, A. (2013). El caso peruano de esterilización forzada. Centro de Recursos Interculturales del Ministerio de Cultura de Perú. https://centroderecursos.cultura.pe/sites/default/files/ $\mathrm{rb} / \mathrm{pdf} /$ ballocc81n-gutierrez-alejandra-el-caso-peruano-de-esterilizacion-forzada-en-mi-cuerpo-no-es-delito-kacc81llpay-warmi-derrama-magisterial-marzo-2013.pdf

Barber, M. y Pope, J. C. (2019). Conservatism in the era of Trump. Perspectives on Politics, 17(3), 719-736. https://doi. org/10.1017/S153759271900077X

Beller, J. L. (2006). The cinematic mode of production: Attention economy and the society of the spectacle. University Press of New England, Hanover and London.

Beller, J. L. (2010) Grammar of the McMultitudes: The labor (malue) of theory. Communication and Critical/Cultural Studies, 7(1), 106-113. https://doi. org/10.1080/14791420903533127

Beller, J. L. (2018). The message is murder: Substrates of computational capital. Pluto Press.

Beller, J. L. (2021). The world computer: Derivative conditions of racial capitalism. Duke University Press,

Crogan, P. y Kinsley, S. (2012). Paying attention: Towards a critique of the attention economy. Culture Machine, 13. https://culturemachine.net/ wp-content/uploads/2019/01/4631025-1-PB.pdf 
Digital Spy. (2018, 30 de agosto). Racist stereotypes in $T V$ and film that white people don't see [Video]. YouTube. https://www.youtube.com/ watch?v=EKAAtHARb4M

Dovidio, J. F., Gaertner, S. L. y Pearson, A. R. (2016). Aversive racism and contemporary bias. En C. G. Sibley y F. K. Barlow (Eds.), The Cambridge handbook of the psychology of prejudice (pp. 267-294). Cambridge University Press. https://doi. org/10.1017/9781316161579.012

Espinoza, F. (2002). El Quinto Suyo. Afrodescendientes en el Perú [Película documental]. Cimarrones.

Estupiñan Achury, L. (2020). COVID-19 y fragilidad del Estado de derecho en América Latina. Revista de la Academia Colombiana de Jurisprudencia, 1(371), xvii-xxx. http://revistaacademiacolombianajurisprudencia.acj. org.co/index.php/revista acj/article/view/84

Fanon, F. (2008). Pele negra, máscaras brancas (Trad. R. da Silveira). EDUFBA. (Trabajo original publicado en 1952)

Franck, G. (2019). The economy of attention. Journal of Sociology, 55(1), 8-19. $\quad$ https://doi. org/10.1177/1440783318811778

Goldhaber, M. (2006). The value of openness in an attention economy. First Monday, 11(6). https://firstmonday.org/ ojs/index.php/fm/article/down$\underline{\text { load} / 1334 / 1254 \text { ?inline }=1}$

Gramsci, A. (1971). Selections from the prison notebooks (Q. Hoare y G. NowellSmith, Eds.). Lawrence and Wishart.
Heindrichs, T. I. L. M. (2019). (Re)branding Tokyo: coexisting views of Tokyo in the Tokyo 2020 audiovisual advertising campaign [Tesis de maestría, University of Glasgow]. Repositorio institucional de la Universidad de Glasgow. http://theses.gla. ac.uk/41169/1/2019HeindrichsMres edited.pdf

Hoyos, R. (2016). Branding, el arte de marcar corazones. Ecoe Ediciones.

Jensen, R. (2015). "You're the nigger, baby, it isn't me": The willed ignorance and wishful innocence of white America. En G. Yancy (Ed.), White self-criticality beyond anti-racism: How does it feel to be a white problem? (pp. 85100). Lexington Books.

Khajeheian, D. y Ebrahimi, P. (2020). Media branding and value co-creation: Effect of user participation in social media of newsmedia on attitudinal and behavioural loyalty. European Journal of International Management. https://doi.org/10.1504/ EJIM.2020.10020735

Mancinas-Chávez, R., Ruiz-Alba, N. y MartínJiménez, C. (2019). Comunicación y estructura invisible de poder: fondos de inversión en el accionariado de las empresas mediáticas. El Profesional de la Información, 28(6), Artículo e280601. https://doi.org/10.3145/ epi.2019.nov.01

Martínez, M. (2010). Entrevista a Teun van Dijk. Sobre el Chile actual, el racismo y nuestros mass media. «Los medios de comunicación en Chile son parte del problema del racismo, y no de la solución». Revista Austral de Ciencias Sociales, (18), 121-129. https:// doi.org/10.4206/rev.austral.cienc. soc.2010.n18-07 
Martinot, S. (2015). Whiteness, democracy, and the hegemonic mind. En G. Yancy (Ed.), White self-criticality beyond anti-racism: How does it feel to be a white problem?(pp. 167-188). Lexington Books.

McMillan Cottom, T. (2020). Where platform capitalism and racial capitalism meet: The sociology of race and racism in the digital society. Sociology of Race and Ethnicity, 6(4), 441-449. https:// doi.org/10.1177/2332649220949473

Mills, C. W. (1991). Alternative epistemologies. En L. M. Alcoff (Ed.), Epistemology: The big questions (pp. 392-410). Blackwell.

Mills, C. W. (2007). White ignorance. En S. Sullivan y N. Tuana (Eds.), Race and epistemologies of ignorance (pp. 11-38). State University of New York Press.

Motta, A. (2011). La «charapa ardiente» y la hipersexualización de las mujeres amazónicas en el Perú: perspectivas de mujeres locales. Sexualidad, Salud y Sociedad (Rio de Janeiro), (9), 29-60. https://doi.org/10.1590/S1984$\underline{64872011000400003}$

Österholm, M. (2010). The ontology of beliefs from a cognitive perspective. En F. Furinghetti y F. Morselli (Eds.), MAVI15: Ongoing research on mathematical beliefs (pp. 35-46). Università degli Studi di Genova, Dipartimento di Matematica.

Perniola, M. (2004). The sex appeal of the inorganic: Philosophies of desire in the modern world (Trad. M. Verdicchio). Continuum. (Trabajo original publicado en 2000)
Rabaka, R. (2010). Forms of fanonism. Frantz Fanon's critical theory and the dialectics of decolonization. Lexington Books.

Rochabrún, G. Drinot, P. y Manrique, N. (2014). Racismo, ¿solo un juego de palabras? Debate a partir del conversatorio: «Racismo y desigualdad en la historia del Perú», del Ministerio de Cultura. Ministerio de Cultura; Instituto de Estudios Peruanos.

RT en Español (2014, 5 de mayo). Los medios en Perú alientan la discriminación racial [Video]. YouTube. https://www. youtube.com/watch?v=4W-DMw9LoTE

Santos Rutschman, A. (2021). Social media self-regulation and the rise of vaccine misinformation. University of Pennsylvania Journal of Law and Innovation. Publicación anticipada en línea. https://doi.org/10.2139/ ssrn. 3782197

Stamps, D. (2020). Race and media: A critical essay acknowledging the current state of race-related media effects research and directions for future exploration. Howard Journal of Communications, 31(2), 121-136. https:// doi.org/10.1080/10646175.2020.1714 513

Steyerl, H. (2009). In defense of the poor image. E-flux Journal, (10). https:// www.e-flux.com/journal/10/61362/ in-defense-of-the-poor-image/

Sullivan, S. (2014). Good white people: The problem with middle-class white anti-racism. State University of New York Press. 
TeleSUR tv. (2014, 26 de septiembre). ONU recomienda a $T V$ peruana sacar de programación programas racistas [Video]. YouTube. https://www.youtube.com/watch?v=3t3jNTf9gBM

Tufekci, Z. (2013). "Not this one": Social movements, the attention economy, and microcelebrity networked activism. American Behavioral Scientist, 57(7), 848-870. $\underline{\text { https://doi. }}$ org/10.1177/0002764213479369

Universidad del Pacífico. (2019, 21 de marzo). Discriminación en el Perú [Video]. YouTube. https://www.youtube.com/ watch?v=wIQSxGISJbs

Valdivia Vargas, N. (2013). Las organizaciones de la población afrodescendiente en el Perú: Discursos de identidad y demandas de reconocimiento. GRADE.

Zavala, V. y Vich, V (2017). Del racismo a la racialización: los argumentos sobre la desigualdad en el Perú. En V. Zavala y M. Back (Eds.), Racismo y lenguaje (pp.185-228). Fondo Editorial PUCP. 